\title{
Modelagem de uma célula a combustível a óxido sólido no software Aspen Plus ${ }^{\circledR}$
}

\author{
Guaitolini, S. V. M. ${ }^{1 *} ;$ Fardin, J. F. ${ }^{2}$; Encarnação, L. F. ${ }^{3}$
}

1, 2, 3 Programa de Pós-Graduação em Engenharia Elétrica, Universidade Federal do Espírito Santo, Vitória, ES, Brasil. * e-mail: stefani.melo@ufes.br, jussara.fardin@ufes.br, lucas@ele.ufes.br

\section{Resumo}

Nas últimas décadas, o interesse nas células a combustível a óxido sólido vem aumentando e o seu uso tornando-se cada vez mais frequente para a geração de energia elétrica estacionária. Ao mesmo tempo, os softwares atualmente existentes usados para analisar o comportamento destas células não apresentam uma plataforma de simulação completa para tal estudo. Com uma modelagem computacional que permita uma análise de desempenho sob várias condições de operação, é possível encontrar o ponto ótimo de funcionamento da célula. Este trabalho pretende preencher esta lacuna ao apresentar uma modelagem completa de uma célula a combustível a óxido sólido desenvolvida para o software Aspen Plus. O resultado desta modelagem permitiu a obtenção dos valores de recirculação anódica e fluxo de oxigênio para o anodo, $5 \%$ e $27 \%$ respectivamente, que alcançaram uma potência de $180 \mathrm{~kW}$ entregue pela célula sem a necessidade de aumentar o fluxo de combustível. Pôde-se concluir que a modelagem da SOFC é possível encontrar o ponto ótimo de operação, sem a necessidade de realizar testes na célula e evitando assim seu desgaste.

\begin{abstract}
In the last decades, the interest in solid oxide fuel cells has been increasing and its use is becoming more frequent for the generation of stationary electric power. At the same time, the existing software used to analyze the behavior of these cells does not present a complete simulation platform for such a study. With a computational modeling that allows a performance analysis under various operating conditions, it is possible to find the optimal point of operation of the cell. This work intends to fill this gap by presenting a complete modeling of a solid oxide fuel cell developed for Aspen Plus software. The result of this modeling allowed to obtain the values of anodic recirculation and oxygen flow for the anode, $5 \%$ and $27 \%$ respectively, which reached a power of $180 \mathrm{~kW}$ delivered by the cell without the need to increase the fuel flow. It can be concluded that SOFC modeling it is possible to find the optimal point of operation, without the need to perform tests on the cell and thus avoid its wear.
\end{abstract}

Keywords (Palavras chaves): SOFC (célula a combustível a óxido sólido), modeling (modelagem), Aspen Plus.

\section{Introdução}

Células a combustível são dispositivos que convertem a energia química dos combustíveis diretamente em energia elétrica. Um tipo de célula a combustível é a célula a combustível a óxido sólido (SOFC) que, diferente da maioria das outras células a combustível, pode ser alimentada por gás natural [1]. O estudo deste tipo de célula é termodinâmico e elétrico, porque é necessário realizar o balanço de energia e o balanço de massa para então realizar o estudo de geração de energia elétrica. Além disso, é necessário o estudo da conversão dos componentes do gás natural, tais como metano, etano, propano e butano em hidrogênio, sendo este o combustível necessário para a geração de energia elétrica [2].

A SOFC possui o eletrólito constituído por material cerâmico com temperatura de funcionamento entre $600^{\circ} \mathrm{C}$ e $1000^{\circ} \mathrm{C}$. Esta alta temperatura permite que seja realizada internamente a reforma do gás natural, que é uma rápida eletrocatálise sem a necessidade de metal nobre para compor o catalisador. Além disso, a alta temperatura de seus produtos permite a cogeração de energia elétrica. Este tipo de célula pode alcançar eficiência de $70 \%$ quando operar em ciclos combinados de calor e potência [3-5]. 


\section{Blucher Proceedings \\ VIII Encontro Científico de Física Aplicada}

As SOFC possuem comportamento elétrico, mas suas reações internas são químicas e, portanto, respondem às leis termodinâmicas. Então, para a realização de uma modelagem é necessário que suas equações e software utilizados respeitem as leis termodinâmicas de funcionamento [6].

O software a ser utilizado é o Aspen Plus, que é um simulador para análise de processos com uma vasta biblioteca de propriedades físicas e termodinâmicas. Esta vasta biblioteca permite resolver o balanço de massa e de energia dos processos ao usar uma técnica modular sequencial para cada unidade individual do estudo [7].

Neste trabalho foi realizada uma modelagem de uma célula a combustível a óxido sólido tubular no software Aspen Plus, cuja reforma do gás natural ocorre em seu interior. A reforma é realizada com o vapor de água que é um dos constituintes do gás que sai do anodo. Também foi considerado na simulação a utilização dos gases de exaustão para aquecimento do ar atmosférico e gás natural na célula. $O$ objetivo deste trabalho foi trazer uma modelagem de uma SOFC, permitindo que, em trabalhos futuros, várias simulações de operação possam ser realizadas e sendo identificado o ponto ótimo de operação para cada realidade onde a célula será implantada.

\section{Modelagem no Aspen Plus}

Na Figura 1 está apresentado o modelo para a SOFC realizado no Aspen Plus. Como o software não possui um modelo para este tipo de célula, foi necessário utilizar dez blocos do software para simular a célula: dois tocadores de calor, um ejetor, dois heaters, dois reatores, um separador, um divisor de fluxo e um combustor, disponibilizadas pelo software para emular as partes constituintes da célula a combustível.

Para a realização deste modelo foram realizadas as seguintes considerações: a célula opera em estado estacionário; não varia sua temperatura; o modelo é o caixa-preta; a reforma é um processo adiabático; os íons que reagem não podem ser modelados no Aspen Plus e não ocorre queda de pressão no interior da célula.
Nas Subseções 2.1 a 2.7 serão descritos os blocos utilizados na modelagem e seus comportamentos.

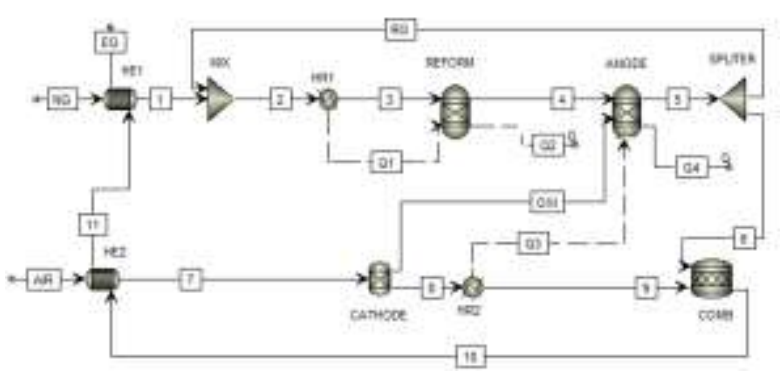

Figura 1: Simulação da SOFC no Aspen Plus.

\subsection{Aquecimento dos gases de entrada}

$\mathrm{O}$ ar atmosférico (AIR) é aquecido no trocador de calor (HE2) ao entrar na célula, devido a troca de calor realizada com os gases provenientes do combustor (COMB). No trocador de calor os gases apenas trocam calor, sem qualquer reação entre si.

Ao passar pelo HE2 a temperatura do ar atmosférico é mais alta do que a temperatura de entrada e mais baixa que a temperatura de operação da célula. Esta condição é importante para o controle de temperatura da célula, pois seus componentes não se mantêm íntegros em temperaturas superiores a $1000^{\circ} \mathrm{C}$ [8].

No trocador de calor (HE1), o gás natural (NG) é aquecido com os gases provenientes do HE2 e chega na próxima etapa do processo com uma temperatura mais alta do que aquela com a qual chegou no trocador de calor. Isto é importante para que não ocorram altos gradientes de temperatura quando o gás natural entrar em contato com os gases de recirculação. Isto evita que ocorra a formação de carbono sólido, o que levaria ao entupimento dos poros do reformador e do anodo [9].

\subsection{Mistura entre os gases de recirculação e gás natural}

No bloco chamado de MIX, o gás natural é misturado aos gases de recirculação, denominado de RG, para que então possa ser reformado e fornecer à célula o gás hidrogênio necessário para seu funcionamento. Nesta etapa do processo não ocorre reação entre os gases. 


\section{Encontro Científico de Física Aplicada}

\subsection{Reforma dos gases}

Os gases que constituem o gás natural devem ser reformados para fornecer o hidrogênio que a célula necessita para funcionar. Este processo de reforma acontece no reformador (REFORM), onde os gases, que constituem o gás natural, sofrerão a reforma, conforme descrito nas Equações 1 a 4 . O monóxido de carbono produzido na reforma, também reagirá com o vapor de água, chamada reação de shift, que produz hidrogênio e gás carbônico, conforme Equação 5:

$$
\begin{gathered}
\mathrm{CH}_{4}+\mathrm{H}_{2} \mathrm{O} \rightarrow \mathrm{CO}+3 \mathrm{H}_{2} \\
\mathrm{C}_{2} \mathrm{H}_{6}+2 \mathrm{H}_{2} \mathrm{O} \rightarrow 2 \mathrm{CO}+5 \mathrm{H}_{2} \\
\mathrm{C}_{3} \mathrm{H}_{8}+3 \mathrm{H}_{2} \mathrm{O} \rightarrow 3 \mathrm{CO}+7 \mathrm{H}_{2} \\
\mathrm{C}_{4} \mathrm{H}_{10}+4 \mathrm{H}_{2} \mathrm{O} \rightarrow 4 \mathrm{CO}+9 \mathrm{H}_{2} \\
\mathrm{CO}+\mathrm{H}_{2} \mathrm{O} \rightarrow \mathrm{CO}_{2}+\mathrm{H}_{2}
\end{gathered}
$$

A temperatura de saída neste bloco é menor, pois as reações que acontecem necessitam de absorverem energia para acontecerem. Então foi inserido um bloco chamado de HR1, que tem a função de simular a diminuição da temperatura. Assim, o HR1 informa o calor Q1 utilizado na reforma. Isto serve para calcular a temperatura de saída do reformador, garantindo que Q2 seja sempre zero. Isto é necessário porque a reforma deve ser sempre adiabática.

\subsection{Reações no Anodo}

Os gases provenientes da reforma são $\mathrm{H}_{2}, \mathrm{H}_{2} \mathrm{O}, \mathrm{CO}$, $\mathrm{CO}_{2}$ e $\mathrm{CH}_{4}$. O metano está presente porque o modelo de reforma implementado no bloco RERFORM do software Aspen Plus não simula a reforma total deste gás. A reforma do resto do metano e também a reação do hidrogênio com o oxigênio irá acontecer no anodo. $A$ principal reação que acontece no anodo é descrita pela Equação 6. É importante ressaltar os modelos usados pelo Aspen Plus não considerada as etapas iônicas das reações.

$$
\mathrm{H}_{2}+0,5 \mathrm{O}_{2} \rightarrow \mathrm{H}_{2} \mathrm{O}
$$

O bloco que modela o anodo no Aspen Plus é um reator chamado ANODE, com temperatura de funcionamento fixada em $910^{\circ} \mathrm{C}$ e fornece calor $\mathrm{Q} 4$.

\subsection{Gases de Recirculação}

Os gases de recirculação são divididos de maneira que se mantenha uma proporção entre vapor/carbono de 2 no reformador. Essa proporção evita a formação de carbono sólido, que poderia levar a célula a um mau funcionamento e/ ou sua desativação. Split é o bloco que faz a divisão entre a quantidade dos gases da exaustão que vai para recirculação e a quantidade que vai para o combustor.

\subsection{Fornecimento de oxigênio}

O ar atmosférico ao ser aquecido, devido à troca de calor que aconteceu no HE2, passa para outro bloco chamado de CATHODE, que possui a função de separar do ar atmosférico a quantidade de oxigênio necessária para a reação descrita na Equação 6. Nesta etapa é utilizado um recurso do Aspen Plus chamado Calculator, que possui a função de calcular a vazão de oxigênio necessária para que a reação descrita na Equação 6 ocorra. A Equação 7 demonstra o cálculo realizado para se determinar a quantidade necessária de oxigênio:

$$
\mathrm{OXI}=0,5 .(\mathrm{Uf}) .\left(\mathrm{m}_{\mathrm{H} 2}\right)
$$

Onde: Uf é o fator de utilização do hidrogênio e $\mathrm{m}_{\mathrm{H} 2}$ é a quantidade de hidrogênio produzida nas reações descritas pelas Equações 1 a 5 .

Para representar as reações do catodo foi necessário inserir o bloco HR2, que simula o calor retirado do anodo para a reação eletroquímica que acontece entre o oxigênio e os elétrons recebidos. O calor Q3 é ajustado para que a temperatura de saída do catodo seja a mesma do anodo, ou a mais próxima possível.

\subsection{Queima dos gases}

Todos os gases que saem do anodo e do catodo se encontram no combustor, denominado de COMB. Nele os gases de saída do anodo $\left(\mathrm{H}_{2}, \mathrm{H}_{2} \mathrm{O}, \mathrm{CO}\right.$ e $\left.\mathrm{CO}_{2}\right)$, se encontram com os gases de saída do catodo $\left(\mathrm{N}_{2}, \mathrm{O}_{2}\right.$, $\mathrm{CO}_{2}, \mathrm{H}_{2} \mathrm{O}$ e Ar). Os únicos gases capazes de reagirem nas condições de temperatura e pressão que existem no combustor são $\mathrm{H}_{2}$ e CO.

$\mathrm{O} \mathrm{H}_{2}$ e $\mathrm{CO}$ reagem com o oxigênio, conforme Equação 8 e 9 , sendo que os gases que constituem a exaustão da célula são os mesmos constituintes do ar atmosférico: $\mathrm{N}_{2}, \mathrm{O}_{2}, \mathrm{CO}_{2}, \mathrm{H}_{2} \mathrm{O}$ e $\mathrm{Ar}$, porém em 


\section{Encontro Científico de Física Aplicada}

concentrações diferentes. É considerado que ocorre uma combustão completa entre $\mathrm{H}_{2}$ e $\mathrm{O}_{2}$, assim como entre $\mathrm{CO}$ e $\mathrm{O}_{2}$.

$$
\begin{aligned}
& \mathrm{H}_{2}+0,5 \mathrm{O}_{2} \rightarrow \mathrm{H}_{2} \mathrm{O} \\
& \mathrm{CO}+0,5 \mathrm{O}_{2} \rightarrow \mathrm{CO}_{2}
\end{aligned}
$$

Quando os gases saem do combustor irão para o HE2, conforme já foi descrito anteriormente.

\subsection{Cálculo da potência produzida pela célula}

A célula a combustível não consegue fazer uma conversão de toda a energia disponível do combustível em potência, devido às perdas internas que levam à geração de calor.

Nesta modelagem, existem quatro tipos de calores: Q1, Q2, Q3 e Q4. Q1 é o calor retirado da célula para realização das reações de reforma e shift. Q2 possui valor zero. Q3 é o calor retirado, para que as reações ocorram adequadamente no catodo. Q4 é um valor de calor existente no anodo, que já foi decrescido pelo resfriamento causado por Q3. Então, para obter a

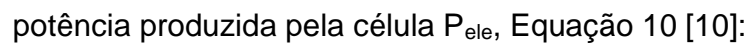

$$
\text { Q4 - Q1 - } P_{\text {ele }}=0
$$

\subsection{Parâmetros utilizados na simulação}

A Tabela 1 apresenta os valores de entrada do software Aspen Plus para o modelo da SOFC.

Tabela 1: Parâmetros utilizados na simulação [9].

\begin{tabular}{|c|c|}
\hline $\begin{array}{c}\text { Dados do Gás } \\
\text { Natural }\end{array}$ & Valores \\
\hline Composição (\%) & $\begin{array}{c}\mathrm{CH}_{4} 81,3 ; \mathrm{C}_{2} \mathrm{H}_{6} 2,9 ; \mathrm{C}_{3} \mathrm{H}_{8} 0,3 ; \\
\mathrm{C}_{4} \mathrm{H}_{10} 0,3 ; \mathrm{CO}_{2} 0,9 ; \mathrm{N}_{2} 14,3\end{array}$ \\
\hline Temperatura $\left({ }^{\circ} \mathrm{C}\right)$ & 200 \\
\hline Pressão (bar) & 3 \\
\hline Vazão (kg/s) & 0,0056 \\
\hline $\begin{array}{c}\text { Dados do Ar } \\
\text { Atmosférico }\end{array}$ & Valores \\
\hline Composição $(\%)$ & $\mathrm{N}_{2} 77,3 ; \mathrm{O}_{2} 20,7 ; \mathrm{H}_{2} \mathrm{O} \mathrm{0,8;} \mathrm{Ar} 1,2$ \\
\hline Temperatura $\left({ }^{\circ} \mathrm{C}\right)$ & 630 \\
\hline Pressão $(\mathrm{bar})$ & 1,013 \\
\hline Vazão $(\mathrm{kg} / \mathrm{s})$ & 0,35 \\
\hline
\end{tabular}

\subsection{Resultados e validação do modelo}

A Tabela 2 demonstra a comparação entre a literatura utilizada como referência e os resultados obtidos.

É importante ressaltar que no modelo da literatura, utilizado como referência para validação do modelo, apenas $14 \%$ do metano foi reformado. Já no Aspen
Plus foi reformado $20 \%$. A consequência de utilizar um maior valor reformado é uma menor temperatura de saída dos gases em comparação ao modelo da literatura. Isto acontece porque esta reação é endotérmica, ou seja, quanto maior for a quantidade reagida, menor será a temperatura de saída dos gases.

Tabela 2: Resultados comparados aos da literatura de referência.

\begin{tabular}{|c|c|c|c|}
\hline Dados & Literatura[11] & $\begin{array}{c}\text { Resultados } \\
\text { encontrados }\end{array}$ & Erro \\
\hline Potência $(\mathrm{kW})$ & 110,8 & 110,81 & $0,01 \%$ \\
\hline $\begin{array}{c}\text { Temperatura } \\
\text { dos gases no } \\
\text { ponto } 2\left({ }^{\circ} \mathrm{C}\right)\end{array}$ & 742 & 744 & $0,27 \%$ \\
\hline $\begin{array}{c}\text { Temperatura } \\
\text { dos gases no } \\
\text { ponto 4 }\left({ }^{\circ} \mathrm{C}\right)\end{array}$ & 611 & 598 & $2,12 \%$ \\
\hline $\begin{array}{c}\text { Temperatura } \\
\text { dos gases no } \\
\text { ponto } 5\left({ }^{\circ} \mathrm{C}\right)\end{array}$ & 910 & 910 & $0 \%$ \\
\hline $\begin{array}{c}\text { Temperatura } \\
\text { dos gases no } \\
\text { ponto } 7\left({ }^{\circ} \mathrm{C}\right)\end{array}$ & 820 & 820 & $0 \%$ \\
\hline $\begin{array}{c}\text { Temperatura } \\
\text { dos gases no } \\
\text { ponto } 10\left({ }^{\circ} \mathrm{C}\right)\end{array}$ & 1005 & 830 & $0,1 \%$ \\
\hline $\begin{array}{c}\text { Temperatura } \\
\text { dos gases no } \\
\text { ponto EG }\left({ }^{\circ} \mathrm{C}\right)\end{array}$ & 830 & 1006 & 0 \\
\hline
\end{tabular}

A Figura 2 mostra o resultado do desempenho da SOFC em resposta a um aumento gradativo da porcentagem em massa do fluxo de recirculação. São apresentados os valores finais de potência em cada ponto monitorado durante as simulações. Foram usados para a simulação os dados de entrada informados na Tabela 1. No Aspen Plus, a porcentagem em massa dos gases é mantida constante. Ao se aumentar a recirculação, aumenta também a quantidade de hidrogênio não utilizada, o que faz com que a célula trabalhe numa temperatura menor, diminuindo a potência gerada.

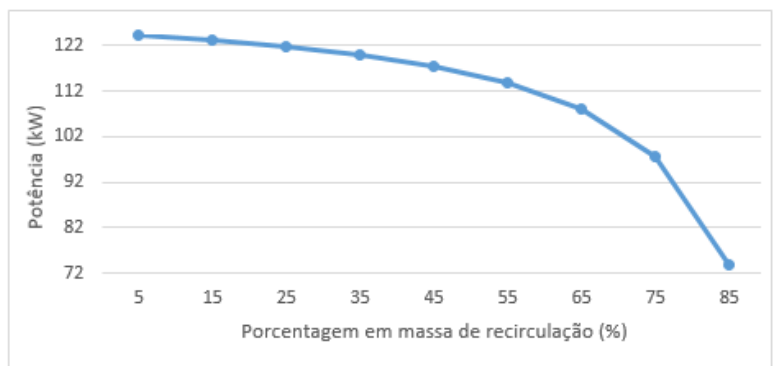

Figura 2: Porcentagem de recirculação versus potência gerada pela célula. 


\section{Encontro Científico de Física Aplicada}

$\mathrm{Na}$ Figura 3 são apresentados os resultados do desempenho da SOFC, considerando uma variação da porcentagem de oxigênio inserida no anodo. Esta variação é obtida deixando de se calcular a quantidade necessária de $\mathrm{O}_{2}$, conforme Equação 7, para reagir com as moléculas de hidrogênio no anodo. Pode-se observar na Figura 3 que ocorre um aumento na potência gerada até quando $27 \%$ do oxigênio do ar atmosférico é transferido para o anodo. É importante observar que a partir de $28 \%$ ocorre uma queda na potência, porque o oxigênio estará em excesso no anodo no percentual de 5,4\%. O excesso de oxigênio leva a um resfriamento da célula, pois ele se encontra a $820^{\circ} \mathrm{C}$. Assim, o oxigênio passa a diminuir a temperatura do anodo e, consequentemente, diminui a potência gerada.

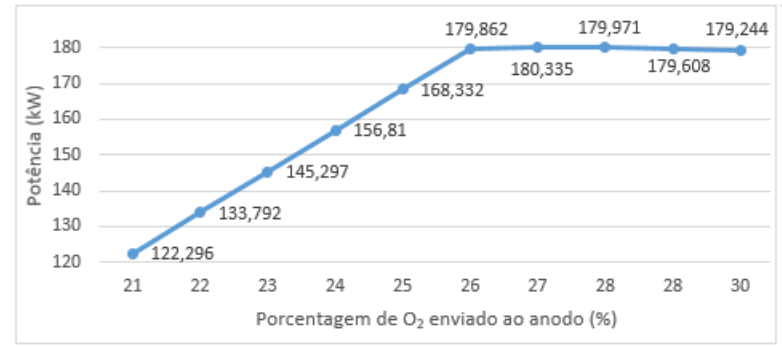

Figura 3: Porcentagem de $\mathrm{O}_{2}$ enviado ao anodo versus potência gerada pela célula.

\section{Conclusões}

Foi desenvolvido e validado um modelo de simulação de uma célula a combustível a óxido sólido no software Aspen Plus. Isso foi possível graças aos blocos existentes. Eles possibilitaram a realização de um modelo que contemplasse todas as partes internas que constituem a SOFC, bem como os processos termodinâmicos internos.

A utilização do Aspen Plus para o presente modelo foi fundamental, porque permitiu realizar estudos termodinâmicos detalhados, tais como estudar passoa-passo as reações internas e suas consequências nos parâmetros de saída, conforme foi mostrado nas Figuras 3 e 4 . Isto tornou a modelagem desenvolvida atrativa para estudos termodinâmicos, pois pode ser encontrado o ponto ótimo de operação da célula sem a necessidade de utilizar a mesma fisicamente. Isto é importante porque testes sucessivos podem ocasionar mau funcionamento e/ou levar a célula a um colapso.

\section{Agradecimento}

Esta pesquisa não teria sido possível sem o apoio financeiro da CAPES.

\section{Referências}

[1] M. Boaro; A. S. Aricò. Advances in Medium and High Temperature Solid Oxide Fuel Cell. International. Centre for Mechanical Sciences. Springer. 2017. pp. 347. ISSN 2309-3706.

[2] C. M. A. Brett; A. M. O. Brett. Electrochemistry: Principles, Methods and Applications. Oxford University Press, 1993. pp. 456.

[3] A. B. Stambouli, E. Traversa. "Solid oxide fuel cells (SOFCs): a review of an environmentally clean and efficient source of energy". Renewable and Sustainable Energy Reviews Vol. 6, 2002. pp. 433-455.

[4] O. Yamamoto. "Solid oxide fuel cells: fundamental aspects and prospects. Electrochemical Acta. Vol. 45, 2000. pp. 2423-2435.

[5] S. C. Singhal. "Advances in solid oxide fuel cell technology". Solid State Ionics. Vol. 135, 2000. pp. 305313.

[6] M. Hauck, S. Herrmann, H. Spliehoff. "Simulation of reversible SOFC with Aspen Plus". International Journal of Hydrogen Energy. Vol. 42, 2017. pp. 10329-10340.

[7] Aspen Plus 10.2 Users Guide, 2000. Aspen Technology, Inc. Cambridge. USA. pp. 936.

[8] S.C. Singhal, K. Kendall. High Temperature Solid Oxide Fuel Cells: Fundamentals, Design and Applications. 1th edition. Elsevier. 2003. pp. 406.

[9] M. Halinen. "Improving the performance of solid oxide fuel cell systems." Thesis of doctor in Technology. Alto University School of Science. 2015. pp. 151.

[10] M. J. Moran and H. N. Shapiro. Fundamental of Engineering Thermodynamics. McGraaw-Hill. 6th edition. 2010. pp. 1012.

[11] S. Campanari. "Thermodynamic model and parametric analysis of tubular SOFC module". Journal of Power Sources. Vol. 92. 2001, pp. 26-34. 